\title{
Effects of cold-water egg shell washing on Salmonella contamination in the shell and its contents
}

\author{
H. Khedmati Morasa ${ }^{1}$ R. Mahmoudi ${ }^{2,3}$, P. Ghajarbeygi ${ }^{3}$, N. Biglari khoshmaram ${ }^{1}$, N. Abasi ${ }^{1}$, Sh. Mousavy $^{4}$
}

\author{
${ }^{1}$ Department of Food Safety and Health, School of Health, Qazvin University of Medical Sciences, Qazvin, Iran \\ ${ }^{2}$ Medical Microbiology Research Center, Qazvin University of Medical Sciences, Qazvin, Iran \\ ${ }^{3}$ Health Products Safety Research Center, Qazvin University of Medical Sciences, Qazvin, Iran \\ ${ }^{4}$ School of Health, Qazvin University of Medical Sciences, Qazvin, Iran \\ Corresponding Address: Razzagh Mahmoudi, Qazvin University of Medical Sciences, Qazvin, Iran \\ Tel: +98-912-7868571; Email: r.mahmodi@yahoo.com \\ Received: 16 Dec 2017; Accepted: 22 Feb 2018
}

\section{* Abstract}

Background: Egg shell washing is one of the simple and inexpensive methods using by many people to clean egg shells.

Objective: In this study, the effects of egg shell washing (with $5^{\circ} \mathrm{C}$ water) on salmonella contamination of shell and its contents was assessment during refrigerated storage for $20 \mathrm{~d}$.

Methods: The 60 eggs samples chosen from Qazvin markets. Egg samples were divided into control (without washing) and cold-washed group with cold water. Salmonella contamination in egg samples was studied before and after washing during cold storage (1, 5, 10, 15, $20 \mathrm{~d})$.

Findings: Salmonella was not isolated in any of the treatments after washing with cold water during refrigerated storage.Washing with cold water followed by storage in the refrigerator led to destroying of Salmonella contamination in eggs. Also, no contamination was found in any of egg contents.

Conclusion: Cold water washing, as a simple and low-cost method at the community level can be used to improve the health of eggs and shells.

Keywords: Eggs, Health, Salmonella, Washing, Shelf life

Citation: Khedmati Morasa H, Mahmoudi R, Ghajarbeygi P, Biglari khoshmaram N, Abasi N, Mosavy Sh. Effects of cold-water egg shell washing on Salmonella contamination in the shell and its contents. J Qazvin Univ Med Sci 2018; 22(2): 83-89. 


\section{بررسى تأثير شستشوى يوسته تخم مرغ با آب سرد بر آلودَّى سالمونلا در يوسته و محتويات آن متان}

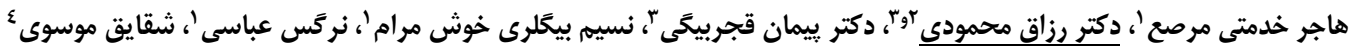

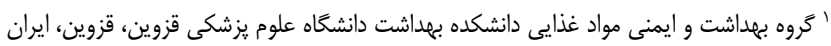

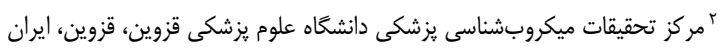

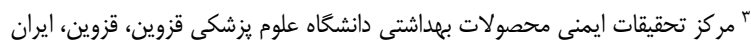

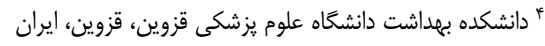

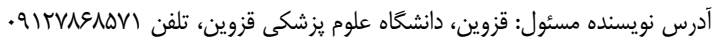

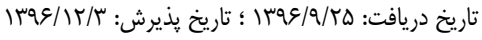

زمينه: شستشوى يوسته تخم مرغ يكى از روشهاى ساده و كم هزينه بوده و امروزه توسط بسيارى از افراد جامعه جهت تميز كردن يوسته تخم مرغ مورد استفاده قرار مى كيرد.

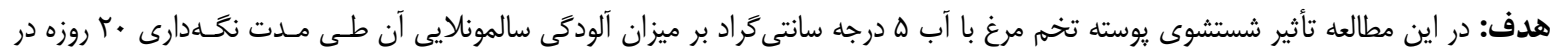
يخجال مورد ارزيابى قرار كرفت.

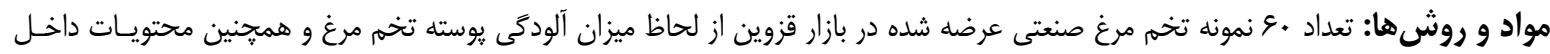

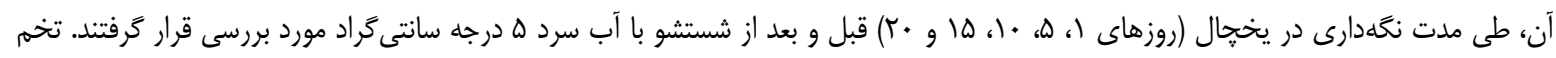

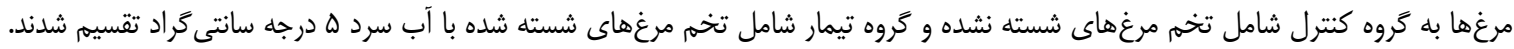

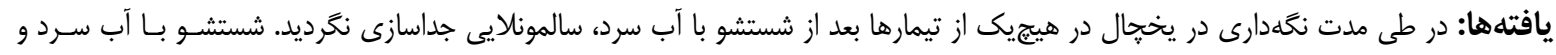

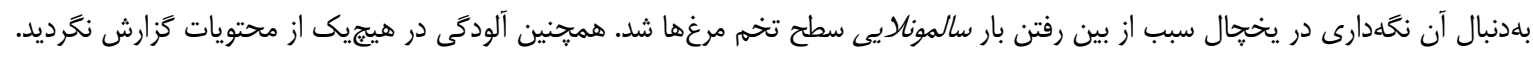

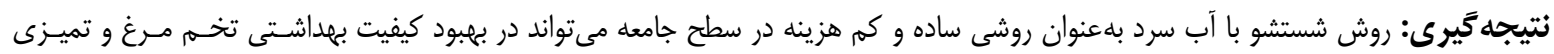

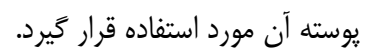

كليدوازهها: تخهم مرغ، بهداشت، سالمونلا، شستشو، ماندًارى

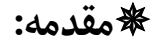

يروتئينهايى با اسيدهاى آمينه ضـرورى و ويتـامينهـاى محلول در تربى ارزش غذايى ويزماى دارد، بلهطورى كـه يروتئين سفيده تخم مرغ به منزله يك يروتئين كامـل در درد

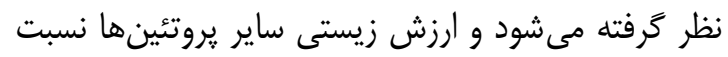

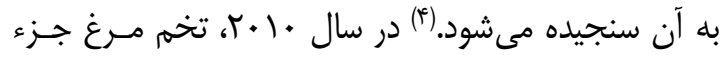
•ا غذاى خطرناك از نظر انتقال بيمارىهاى ناشى از غذا.

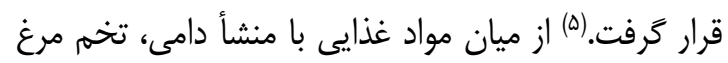

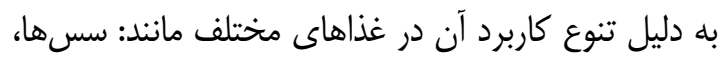
بستنى كه بلهورت خام و يا نسيهـــز مـورد مصـرف قـرار
هر ساله در كشورهاى توسعه يافته بيش از يك سـوم

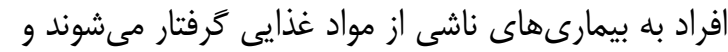

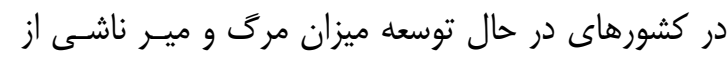

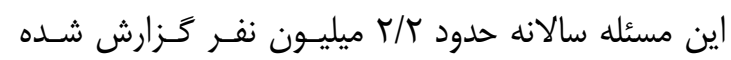

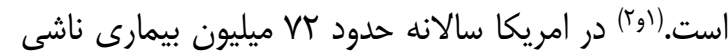
از مواد غذايى كزارش مىشود، اما در ايران بيمـارىهـاى ناشى از غذا تاكنون به صورت كشورى تحت كنترل قـرار

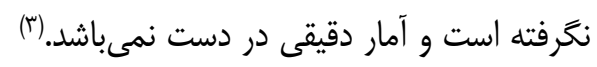

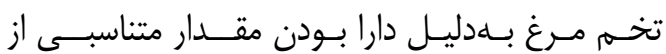


سالمونلا شناسايى شده است اما آخرين طبقهبندى، آنهـا

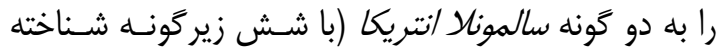

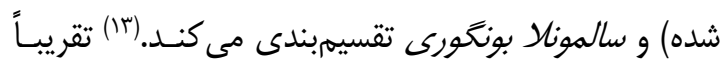

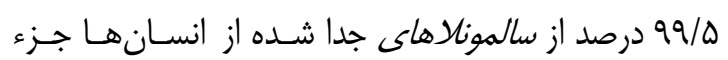

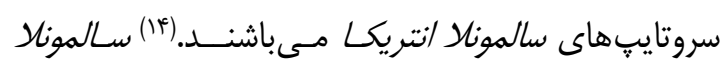

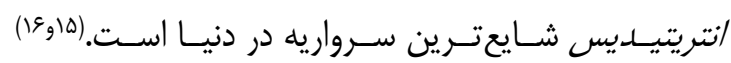

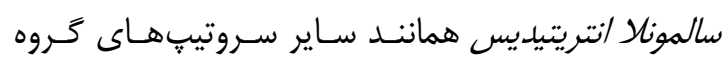

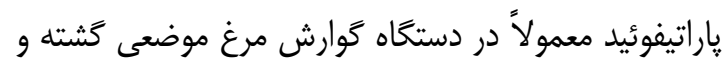

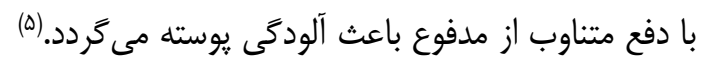

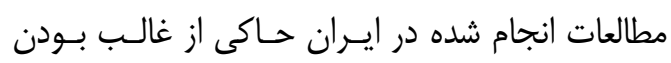

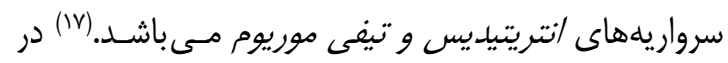

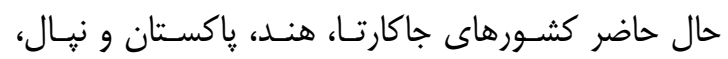

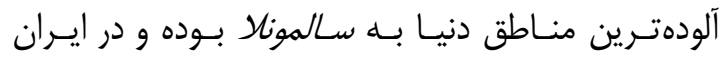
شهرهاى كرمان، هرمزكان، كرمانشاه، كردستان، لرسـتان

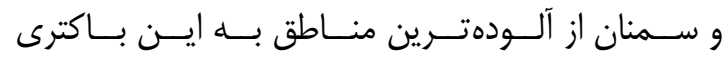

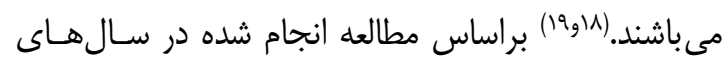

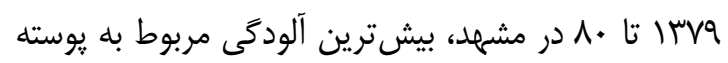

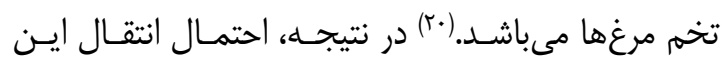

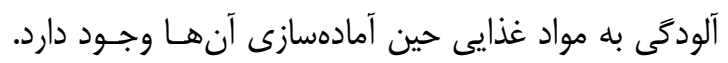

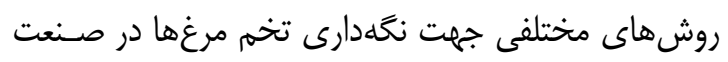

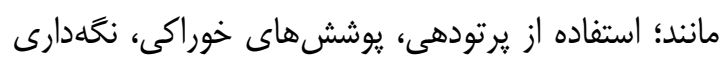

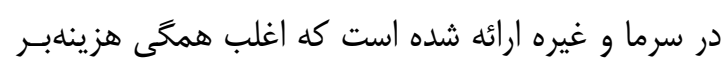

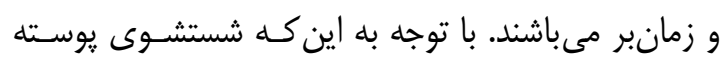

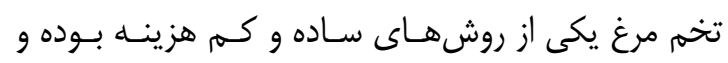

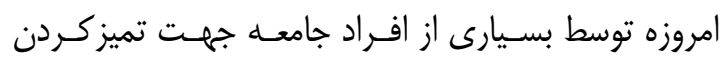

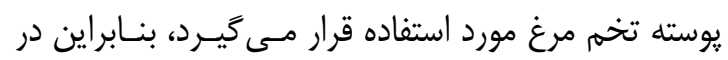

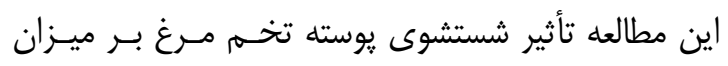

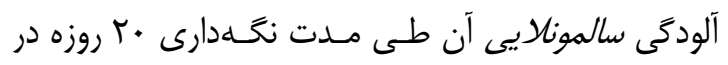
يخجال مورد ارزيابى قرار ترفت.

\section{0 مواد و روشها:}

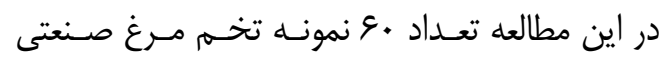

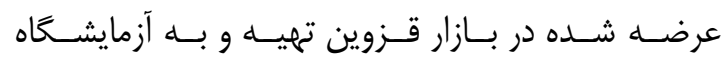

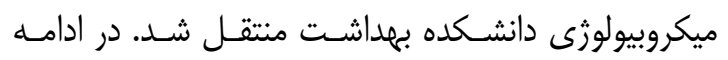

مى گيرد، همواره بلهصورت بالقوه منشـأ آلـودَى و انتقـال بيمارىها به انسان بوده است. (F) امـروزه مطالعـات كســردهاى در ايـن زمينـهـ انجـام مى شود و برخى عوامل عفونى باكتريايى نظير: سـالمونلا،

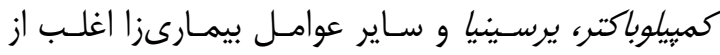

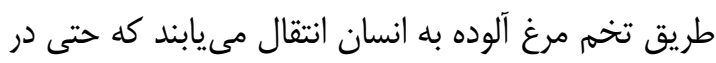

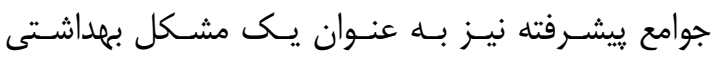

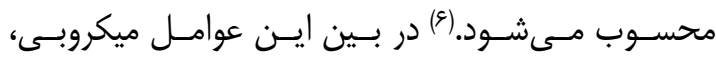

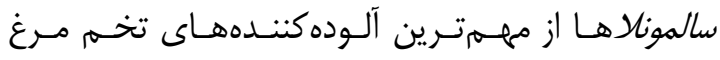

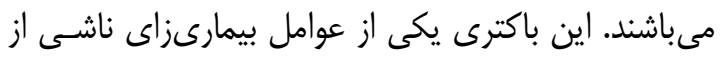

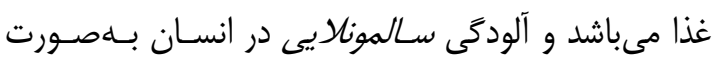

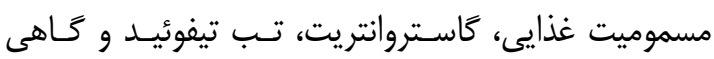

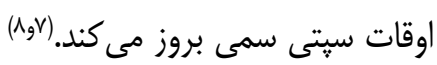

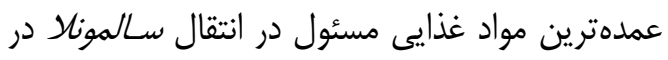

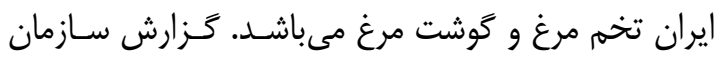

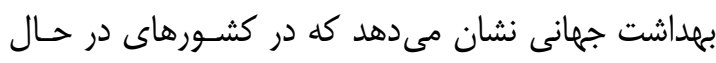

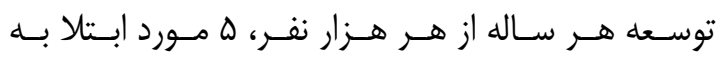

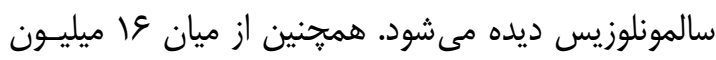

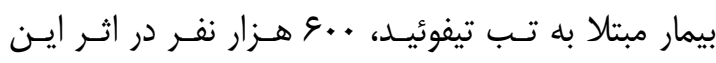

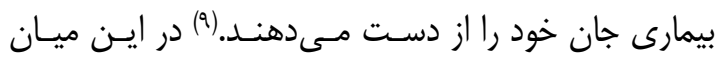

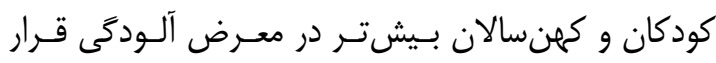

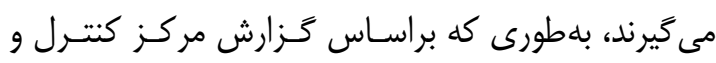

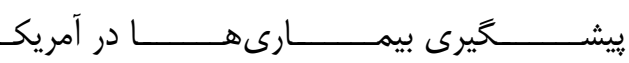
(Centers for disease control and prevention; CDC)

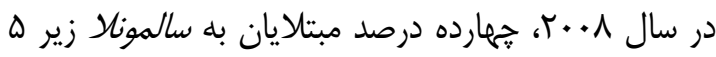

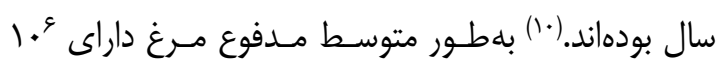

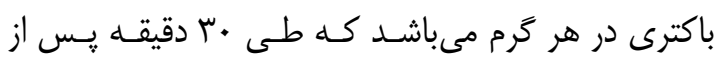

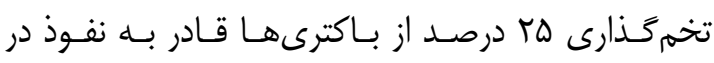
تخم مرغ هستند. تخمارى

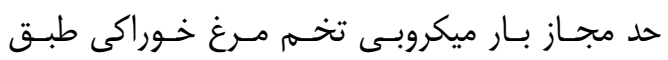

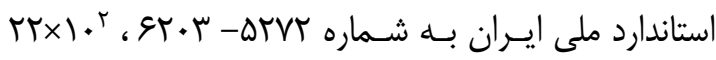

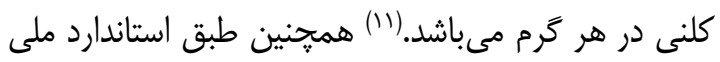

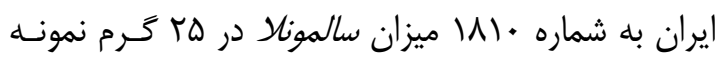

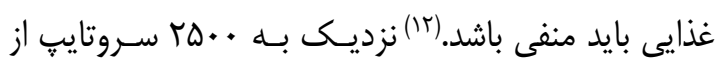


شده و يِييت استريل داخل تخهم مـرغ گرديـده و يـس از

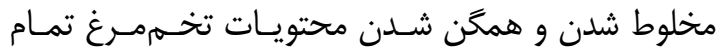

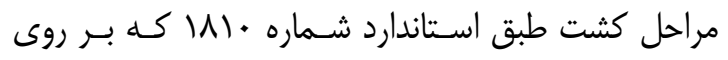

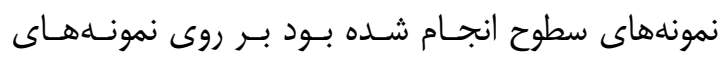
محتويات داخل تخهم مرغها تكرار گرديد.

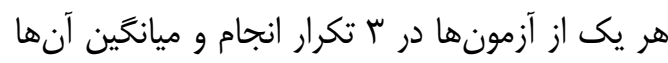
به روش تحليل واريانس يك طرفه با استفاده از نرمافـزار SـSS 19

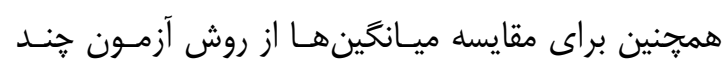
دامنهاى دانكن در سطح احتمال هـ|+> P استفاده شد.

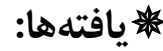

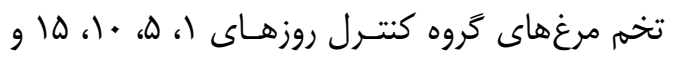

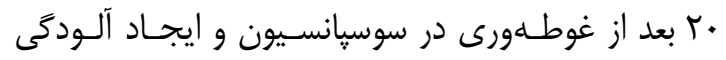
سطحى با دوز مشخصى از باكترى سالمونلا تيفى موريوم

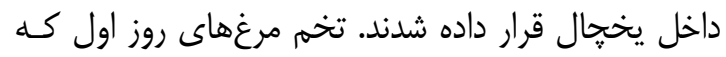

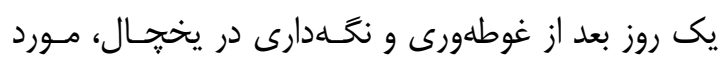

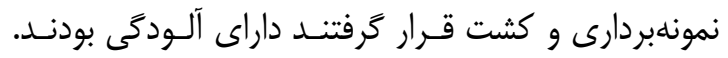

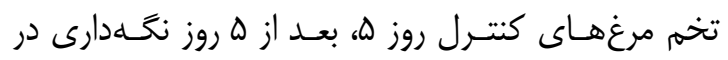

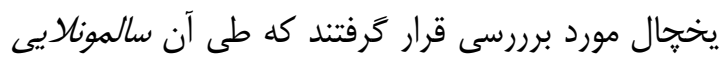

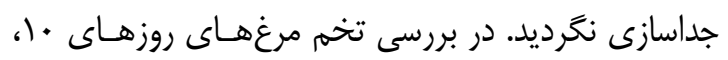

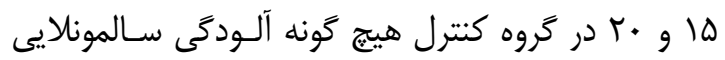

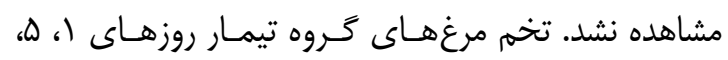

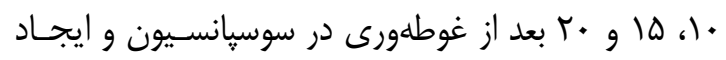

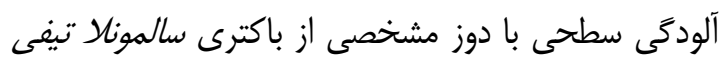

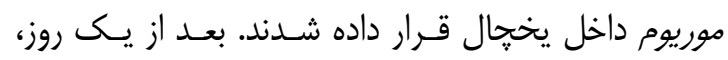

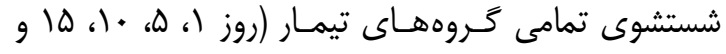

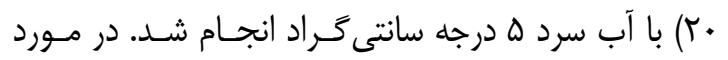

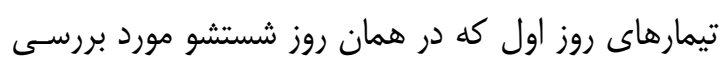

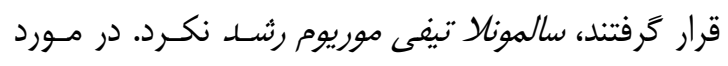

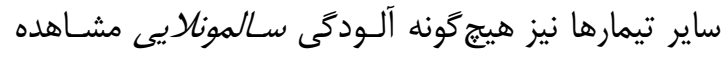
نشد. در مورد محتويات تمامى گروهها (تيمار و كنترل) نيز

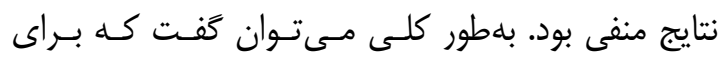

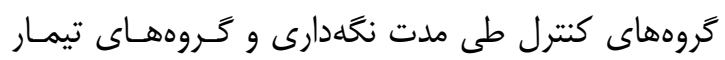

تخم مرغها به كروههاى كنتـرل و تيمـار تقسـيم شـدند.

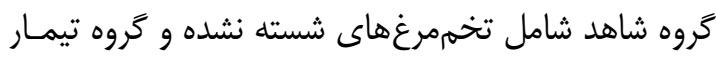

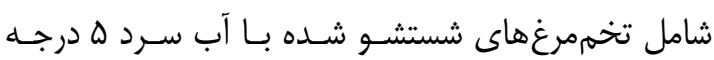

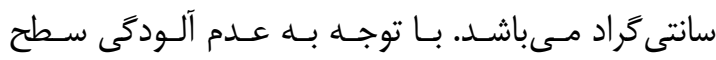
تخمم مرغها، بلهورت مداخله، سوسيانسيونى از سـالمونلا

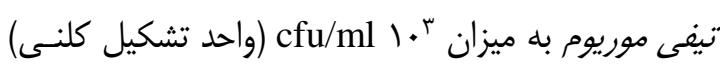

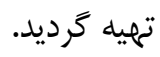

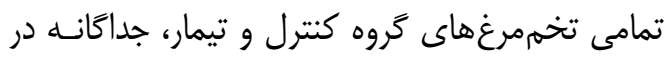

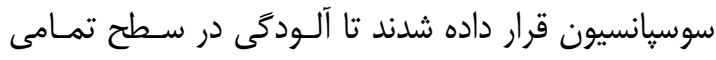

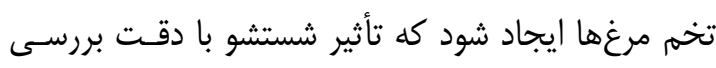

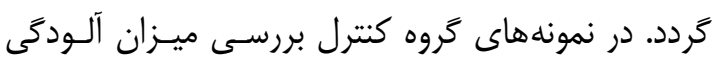

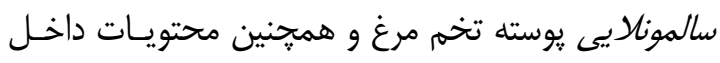

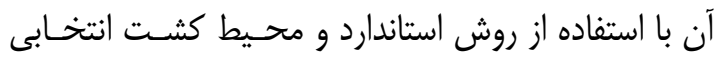

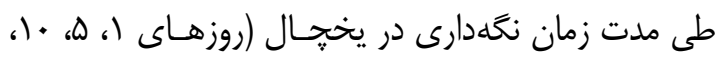

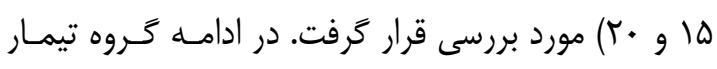

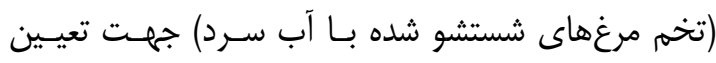

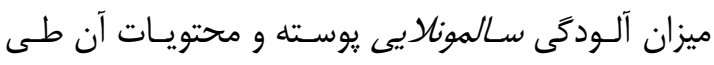

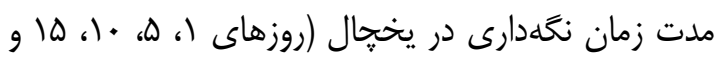

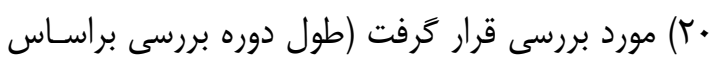

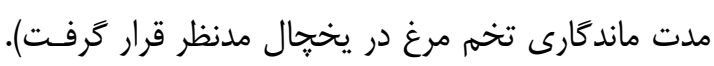

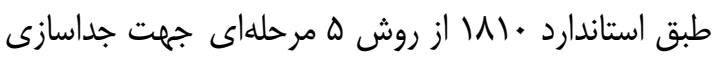

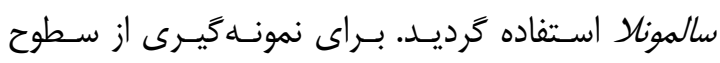

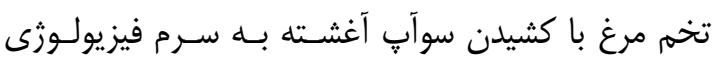

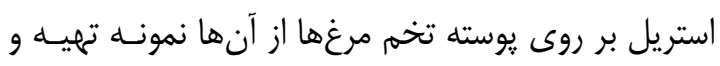

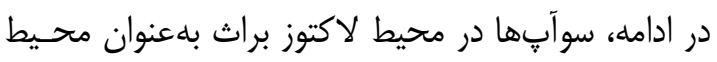

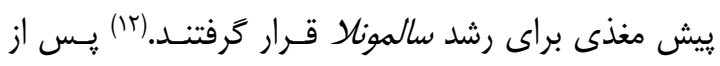
Tr Tاعت انكوباسيون نمونه به محيط TSI (ترييل شوكر

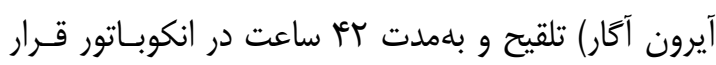

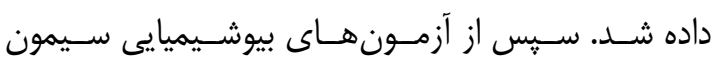

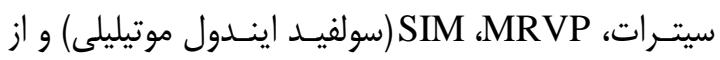

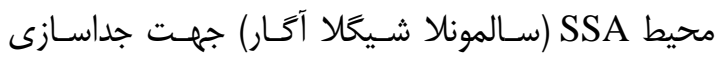

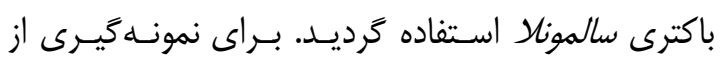

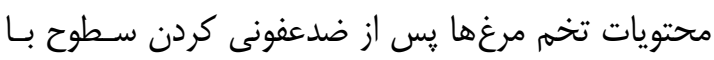
الكل •V درصد، قسمت كيسه هواى تخم مرغهـا سـوراخ 
روشهاى ديخر مى توان به يرتـودهى اشـاره كـرد. بـراى

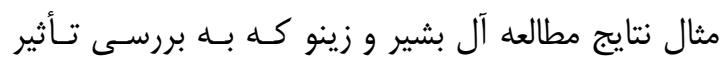

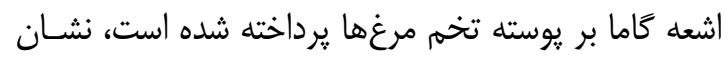

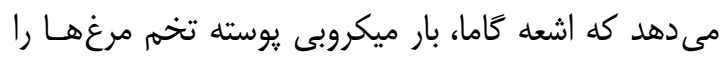
بلطور :شمخيرى كاهش داده است.(r) استفاده از زنجيره

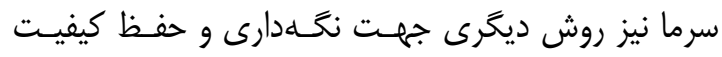

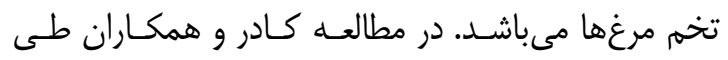

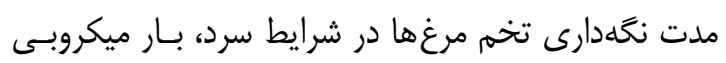

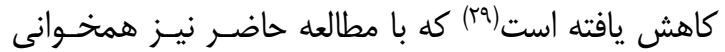

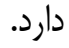

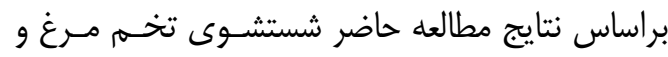

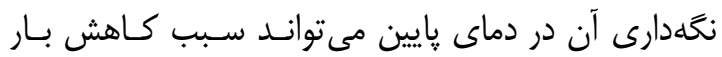
ميكروبى يوسته و همجنين افزايش مانـدكارى ايـن مـاده

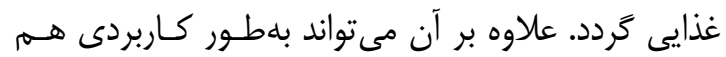

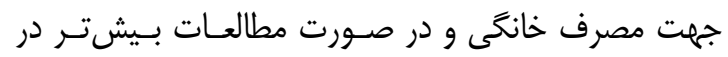

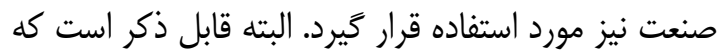
ايجاد شرايط بهينه بــراى افـزايش مانــدارى ايـن مـاده

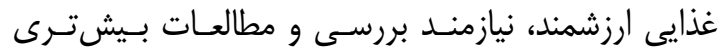

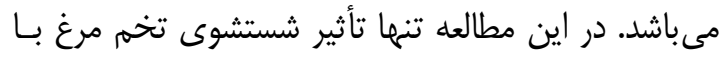

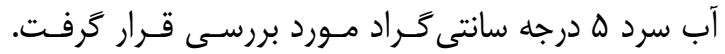
ييشنهاد مى شود تأثير شستشو با دماهاى مختلف نيز مـورد

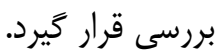

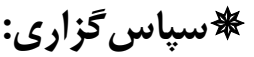

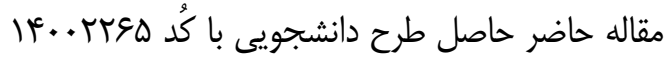

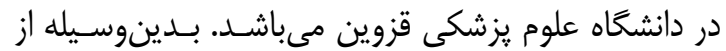
كميته تحقيقات دانشجويى دانشكاه علوم يزشكى قـزوين،

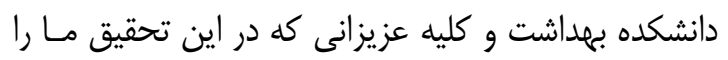
يارى نمودند، تشكر و قدردانى مى نماييم.

\section{مراجع:}

1. Lee S, Kim YY, Lee Y, An G. Rice P1Btype heavy-metal ATPase, OsHMA9, is a metal efflux protein. Plant Physiol 2007; 145(3): 831-42. doi: 10.1104/pp.107.102236.
يس از شستشو تمام مشاهدات منفى بوده و همجنين بين

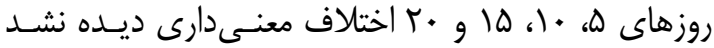

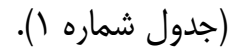

جدول ا - شمارش سالمونلا در نمونهها طى دوره نغكددارى تخم مرغها (cfu/ml)

\begin{tabular}{|c|c|c|c|c|}
\hline \multirow{2}{*}{ روزهاى مورد } & \multicolumn{2}{|c|}{ كنترل } & \multicolumn{2}{|c|}{ تيمار } \\
\hline & يوسته & محتويات & يوسته & محتويات \\
\hline 1 & $\Gamma \digamma / \& \varphi \pm \Gamma / \cdot \Delta^{\mathrm{A}}$ & B. & B. & B. \\
\hline$\Delta$ & • & - & . & - \\
\hline 1. & . & . & - & . \\
\hline 10 & . & . & . & . \\
\hline$r$. & . & . & . & . \\
\hline
\end{tabular}

حروف متفاوت نشان داده شده رديف يك در جدول شـماره ا داراى اختلاف آمارى معنى دارى مى مباشد.

\section{كان بحث و نتيجه كَيرى:}

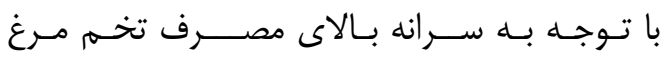

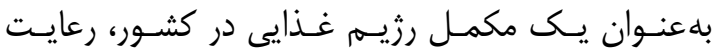

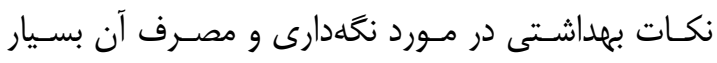

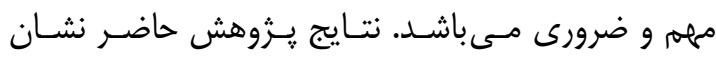

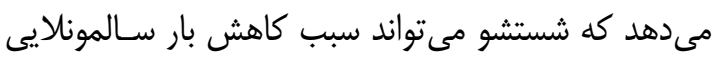
يوسته تخهم مرغ گردد. در ساير مطالعات انجام شده، نتايج

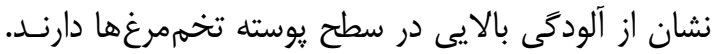

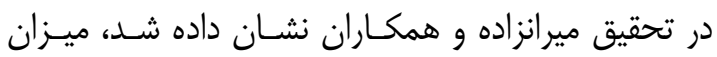

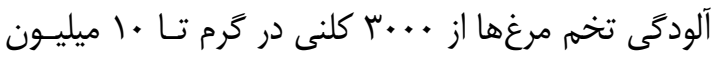

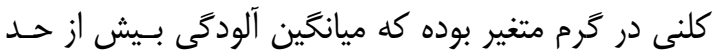

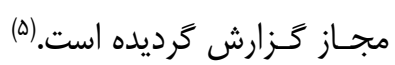
امروزه روشهاى مختلفى در جهت افزايش ماندَّارى

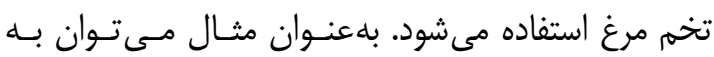

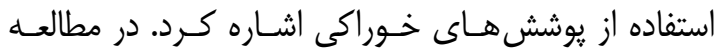

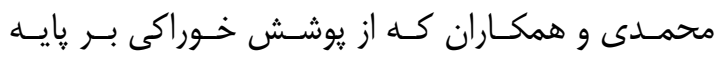
كربوكسى متيل سلولز حاوى اسيد اولئيك استفاده كردهاند

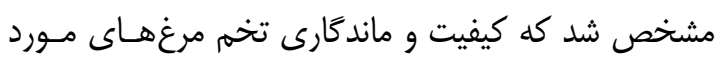

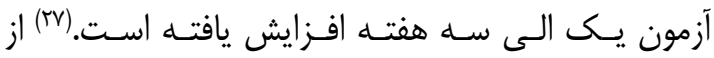


2. Klaassen CD, Watkins JB. Casarett \& Doull's essentials of toxicology: McGraw Hill Professional 2015; 12.

3. Wingender J, Flemming HC. Biofilms in drinking water and their role as reservoir for pathogens. Int J Hyg Environ Health 2011; 214(6): 417-23. doi: 10.1016/j.ijheh.2011.05. 009.

4. Torrico DD. Effects of Emulsion Coatings on the Internal Quality and Shelf Life of Eggs. Food sci Technol: Louisiana State University and Agricultural and Mechanical College; 2010. 27-34.

5. Miranzadeh H, Zahrei Salehi T, Karimi V. The count of aerobic mesophill bacteria and isolate salmonella Spp on egg in Isfahan 1389 [2012]. Veterinary J 2012; 94: 31-6.

6. Favier GI, Escudero ME, de Guzman AMS. Thermal inactivation of Yersinia enterocolitica in liquid egg products. J Food Saf 2008; 28(2): 157-69. doi: 10.1111/j. 1745-4565.2008.00103.x.

7. Liebana E, Garcia-Migura L, Clouting C, Cassar CA, Clifton-Hadley FA, Lindsay EA, et al. Investigation of the genetic diversity among isolates of Salmonella enterica serovar Dublin from animals and humans from England, Wales and Ireland. J Appl Microbiol 2002; 93(5): 732-44. doi: 10. 1046/j.1365-2672.2002.01737.x.

8. Wegener HC, Hald T, Lo Fo Wong D, Madsen M, Korsgaard H, Bager F, et al. Salmonella control programs in Denmark. Emerg Infect Dis 2003; 9(7): 774-80. doi: 10. 3201/eid0907.030024.

9. Ranjbar R, Torabi R, Mirzaie A. Molecular typing of Salmonella enteritidis strains isolated in several laboratory centers in Tehran by ERIC-PCR. J Kurdistan Univ Med Sci 2013; 18(2): 77-85. [In Persian]

10. Beam A, Garber L, Sakugawa J, Kopral
C. Salmonella awareness and related management practices in US urban backyard chicken flocks. Prev Vet Med 2013; 110(3-4): 481-8. doi: 10.1016/j.prevetmed.2012.12.004. 11. Scott TA, Silversides FG. The effect of storage and strain of hen on egg quality. Poult Sci 2000; 79(12): 1725-9.

12. Institute of Standards and Industrial Research of the Country Sampling and Identification Method. National Iranian Standard No 1810.

13. Hosseinpour M, Sabokbar A, Bakhtiari A, Parsa S. Comparison of bacterial culture, ELISA and PCR techniques for detection of salmonella in poultry meat samples collected from Tehran. J Microbial World 2013; 6(1): 62-72. [In Persian]

14. Ranjbar R, Giammanco GM, Aleo A, Plano MR, Naghoni A, Owlia P, et al. Characterization of the first extendedspectrum $\quad \beta$-lactamase - $\quad$ producing nontyphoidal Salmonella strains isolated in Tehran, Iran. Foodborne Pathog Dis 2010; 7(1): 91-5. doi: 10.1089/fpd.2009.0382.

15. Sasaki Y, Tsujiyama Y, Asai T, Noda Y, Katayama S, Yamada Y. Salmonella prevalence in commercial raw shell eggs in Japan: a survey. Epidemiol Infect 2011; 139(7): $\quad 1060-4$. doi: $10.1017 /$ S0950268810002153.

16. Martelli F, Davies RH. Salmonella serovars isolated from table eggs: an overview. Food Res Int 2012; 45(2): 745-54.

17. Namaei M, Ziaee M, Kafi MG. Prevalence of salmonella contamination in locally (non-industrially) produced eggs in Birjand (2006). J Birjand Univ Med Sci 2009; 16(2): 37-41. [In Persian]

18. FAO, WHO. Food and Agriculture Organization of the United Nations, 20022006.E/C.19/2007.3 
19. Staff AO. Risk assessments of Salmonella in eggs and broiler chickens: interpretative summary: World Health Organization; 2002.8-13.

20. Hamedi A, Parizadeh S, Ghanaat J. Study of contamination to Salmonella in two groups egg (Compiercial and Local). J Mashhad Univ Med Sci 2002; 45(76): 67-71. [In Persian]

21. Shareef A, Al-Sanjary R, Hassan A. Recovery of two types of Salmonella from eggs of range rearing hens and ducks. Iraqi $\mathrm{J}$ Vet Sci 1997; 10(2): 25-8.

22. Amirmozaffari N, Rahmani Z, Iesazadeh K. Evaluation of the level of contamination with Salmonella spp. in red meat, chicken, and domestic and industrial eggs produced in Talesh city and assessment of their antibiotic resistance pattern, Iran. Qom Univ Med Sci J 2013; 7(5). [In Persian]

23. Monadi M, Kargar M, Naghiha A, Mohammadi R. Salmonella contamination of eggs of native Kohgiluyeh va Boyerahmad using PCR1 techniques and the evaluation of drug resistance. Armaghane-danesh. 2014; 19(2): 179-87. [In Persian]

24. Jones DR, Musgrove MT. Pathogen prevalence and microbial levels associated with restricted shell eggs. J Food Prot 2007; 70(9): 2004-7.
25. Folorunsho O, Charles A. Effect of rinses on microbial quality of commercially available eggs and its components before processing from Ilorin in western Nigeria. Bitlis Eren Univ J Sci Technol 2013; 3(2): 44-7. doi: 10.17678/beuscitech.47130.

26. Gole VC, Chousalkar KK, Roberts JR, Sexton M, May D, Tan J, et al. Effect of egg washing and correlation between eggshell characteristics and egg penetration by various Salmonella Typhimurium strains. PloS One 2014; 9(3): e90987. doi: 10.1371/journal. pone.0090987.

27. Mohamadi SH, Ghanbarzadeh B, Sooti M, Ghyasifar SH, Jalali SH. Application of active carboxymethylcellulose - based carboxylic acid containing oleic acid and antimicrobial agents to improve the quality and increase the shelf life of eggs. Iranian Food Sci Technol Res J 2012; 8(2): 235-44. [In Persian]

28. AL-bachir m, Zeinou R. Effect of gamma irradiation on some characteristics of shell eggs and mayonnaise prepared from irradiated eggs. J Food Saf 2006; 26(4): 34860. doi: 10.1111/j.1745-4565.2006. 00054.x. 29. Cader S, Goburdhun D, Neetoo $H$. Assessment of the microbial safety and quality of eggs from small and large-scale hen breeders. J World's Poult Res 2014; 4(4): 75-81. 